\title{
Poema em Prosa e Modernidade Lírica
}

\author{
Antônio Donizeti Pires (UNESP/Araraquara)
}

RESUMO: Este trabalho pretende refletir sobre a história, a teoria, a crítica e a prática do poema em prosa, cujos primeiros esboços se delineiam no Romantismo alemão. Contudo, é no âmbito da literatura francesa que o poema em prosa adquire foros de legitimidade, quando então se caracteriza como modalidade poética transgressora e revolucionária, em compasso com a própria noção de modernidade lírica e fazendo jus, mesmo, à época prosaica que o viu nascer. Sendo, sobretudo, ritmo e imagem, analogia e ironia (nos termos de Octavio Paz), o poema em prosa contribuiu para uma nova consciência e para um novo estatuto do poético, na França e alhures.

PALAVRAS-CHAVE: Poema em prosa; Poesia lírica; Modernidade; Literatura moderna.

ABSTRACT: This paper intends to reflect on the history, theory, criticism and practice of the prose poem, whose first outlines were delineated during the German Romanticism. However, it is within the ambit of French literature the prose poem acquires legitimacy when it is characterized as a transgressive and revolutionary poetic style, in syntony with the concept of lyrical modernity while honouring the prosaic epoch which saw its birth. By being, above all, rhythm and image, analogy and irony (in words of Octavio Paz), the prose poem contributed to a new awareness and a new status of the poem in France and other places.

KEYWORDS: Prose poem; Lyrical poetry; Modernity; Modern literature.

Um

Na contra-mão da revolução utópica, progressista e reformista do longo processo de modernização que o Ocidente tem levado a efeito, a revolução às avessas engendrada pela poesia moderna é caracterizada, essencialmente, pela recuperação da magia ancestral, que invade a linguagem, o fazer poético, a concepção de poesia e o estatuto do poeta. Porém, contraditoriamente, os poetas da modernidade apresentam "a crescente necessidade, especificamente moderna, de [...] intelectualizar a poesia" (FRIEDRICH 1991: 50). Nova epistéme calcada na dissonância, na auto-suficiência e na teleologia, na aguda intelectualidade, no divórcio com a realidade, no hermetismo, na pesquisa formal, na metalinguagem e na intertextualidade exacerbadas, na fantasia ditatorial do poeta e na exploração de seu eu profundo, a poesia da modernidade, na opinião de Hugo Friedrich, quer-se apreciada e valorada por categorias negativas. 
Esses aspectos contraditórios da modernidade lírica são acirrados no poema em prosa, que, ao valer-se da revolução formal e temática propugnada pelo Romantismo, pelo Simbolismo e pela vanguarda, também se insere na tradição da ruptura preconizada por Octavio Paz em Los hijos del limo (1974) e em A outra voz (1990). Ao subverter velhas concepções e ao colocar em xeque a versificação tradicional e os conceitos arraigados de prosa e poesia, o poema em prosa, ao lado de outras conquistas técnicas e expressionais (o verso livre, o estilhaçamento do verso na página, o monólogo interior, a poesia como gnose do eu), contribuiu para uma nova consciência e um novo estatuto do poético.

O poema em prosa não é uma forma fixa, como o soneto, e sua natureza livre e essencialmente proteiforme desencoraja qualquer definição apriorística. Contudo, a obra pioneira de Suzanne Bernard, Le poème en prose de Baudelaire jusqu'à nos jours (1959), procura contornar tais questões espinhosas e, ao mesmo tempo, oferece uma conceituação bastante válida do poema em prosa em geral. Para a autora, "le poème en prose est une organisation au second degré de la prose, une 'forme secondaire', si l'on veut, formant un tout et complète en soi, un univers fermé un poème" (BERNARD 1959: 430; grifos da autora). Bernard recusa a noção do poema em prosa como híbrido e o qualifica como "un genre de poésie particulier, qui si sert de la prose rythmée à des fins strictement poétiques" (1959: 434). Esse novo gênero - ou melhor, essa nova modalidade da poesia lírica - impinge à prosa corrente, lógica, fluente, denotativa e cotidiana, de primeiro grau, suas leis estéticas específicas, caracterizadas por Bernard como "totalité d'effet, concentration, gratuité, intensité" (1959: 439). Por outro lado, o poema em prosa renuncia ao verso, à rima e à metrificação e se fundamenta sobre a união dos contrários, prosa e poesia, de cuja tensão inerente brotam os pares de opostos aproveitados por Bernard na conceituação estética do poema em prosa: a) primeiramente, este se estrutura sob um duplo princípio, poistoma seus elementos estruturais à prosa e se constrói como poema; b) em consequiência, é o resultado da tensão entre a anarquia ou negação destrutiva, que refuta os elementos tradicionais da poesia, e a vontade de organização artística, de maneira nova e livre; c) as duas formas básicas do poema em prosa, na tradição francesa, são o poema formal ou artístico (Bertrand, os parnasianos), mais estrito, e o poemailuminação ou anárquico (Rimbaud, Lautréamont, os surrealistas), que estilhaça os 
limites, as convenções e as noções de ordem, lógica, razão, estrutura, consciência, tempo, espaço, duração... Este se configura, por excelência, como o modus privilegiado de expressão da modernidade, pois exacerba tanto o ritmo e as imagens caóticas, dilaceradas e fragmentadas do inconsciente do poeta, quanto o ritmo e as imagens caóticas, dilaceradas, absurdas e fragmentadas do mundo exterior, em constante metamorfose. Em que pese à funcionalidade, pode-se criticar a estética fechada do poema em prosa proposta por Suzanne Bernard porque esta compromete o caráter heterogêneo e aberto dessa nova modalidade de poesia lírica.

As qualidades inerentes ao poema em prosa, objeto construído de linguagem, são as mesmas do poema em versos tradicional, seja este em forma fixa, seja em versos livres e brancos, pois qualquer poema que mereça realmente o epíteto explora a condensação da linguagem e se perfaz como um todo orgânico, autônomo, fechado em si mesmo como uma esfera: o poema em prosa éo óleo essencial da arte (Huysmans); é o resultado da crise do verso (Mallarmé) que perpassa a poesia finissecular oitocentista; é uma questão de alquimia verbal (Rimbaud), de unidade de efeito(Poe), de expressão da modernidade (Baudelaire), de trabalho com a linguagem, de consciência criativa e de liberdade do poeta. Em suma, o poema em prosa revela-se campo propício para a exploração dos prismas fundamentais da lírica, conforme Ezra Pound: logopéia, fanopéia e melopéia.

Em termos formais, dos vários elementos concernentes ao poema tradicional (verso, metro, estrofe, rima, ritmo e imagem), com exceção do verso e do metro, todos os outros são encontráveis, transfigurados, no poema em prosa. Assim, abolidos o verso e o metro - substituídos por sentenças breves e/ou longas e pelo parágrafo mais distendido da prosa, de certo modo equivalente à estrofe -, constata-se que a rima convencional também é superada, agora explorada em nuanças possíveis pela homofonia (aliteração, assonância, figuras de harmonia, repetições), que explora o estrato fônico e apóia o ritmo. As imagens veiculadas pelo poema em prosa - as do mundo medieval, fantástico e grotesco de Bertrand; as do mundo moderno baudelairiano; as dissonantes de Rimbaud e Lautréamont; as evocações espirituais e interiores dos simbolistas, como em "Asas..." e "Oração ao sol”, de Cruz e Sousa (de Evocações e Missal, respectivamente) - são deliberadamente sugestivas. Conforme 
Suzanne Bernard, "cette esthétique de la suggestion, elle est, au fond, inséparable de l'esthétique même du poème en prose" (1959: 72). O poema em prosa, enfim, deixando de lado entraves maiores como o verso e a metrificação, relativizando o emprego da rima e da estrofe, valoriza essencialmente o ritmo(interior e exterior; analógico e dissonante) e a imagem (interior e exterior; analógica e dissonante) da esfacelada vida

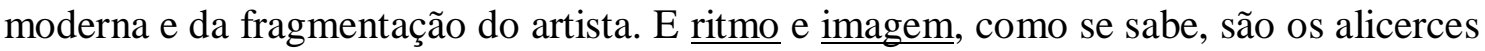
sobre os quais se edificaram as dúbias torres da lírica da modernidade.

\section{Dois}

De modo geral, as origens do poema em prosa ligam-se à importância que a prosa poética adquire, com o Pré-Romantismo e o Romantismo alemães, para a expressão de um novo estado de alma, uma nova concepção de mundo e um novo modo de perquirição do eu, do inconsciente, da natureza. Na França, tal prosa poética aparece em gérmen nas traduções da Bíblia, nas Pensées de Pascal, na oratória de Bossuet, nas máximas de La Rochefoucauld. É exemplar na epopéia em prosa Télémaque (1699), de Fénelon, cuja Lettre à l'Académie (1714) questiona a rigidez do verso tradicional e o engessamento a que a poética clássica constrangera a poesia francesa do século XVIII. À prosa poética pré-romântica e romântica (penso nas divagações de Rousseau, nos romances de Chateaubriand), somam-se as traduções em prosa, para o francês, de poetas alemães, escandinavos, escoceses e ingleses, bem como as pseudotraduções - poemas geralmente escritos em prosa, sob a vaga e a voga ossiânicas de James Macpherson, como se fossem traduções de outros autores, geralmente exóticos e/ou distantes no tempo e no espaço: asChansons Madécasses (1787), de Parny, por exemplo, são breves peças em prosa que, segundo o autor, foram traduzidas do malgache.

É em tal conjuntura que aparecem em revistas de Lyon, desde 1826, os primeiros textos de Aloysius Bertrand (1807 - 1841), considerado o iniciador da poesia em prosa na lírica francesa e aquele que a decanta de seus elementos mais prosaicos, dando-lhe forma artística mais definida e definitiva. O manuscrito de Bertrand, Gaspard de la nuit, vendido ao editor Renduel em 1836, foi publicado em 1842 e traz como subtítulo a expressão "Fantaisies à la manière de Rembrandt et de Callot". Décadas depois, os parnasianos se voltarão para o formalismo pitoresco e pictórico de Bertrand. 
Charles Baudelaire (1821 - 1867), na segunda metade do século XIX, procura aplicar, na pintura da modernidade urbana, o mesmo procedimento que Bertrand aplicara ao fantástico-pitoresco da Idade Média. Mas Baudelaire, para tanto, rompe o estreito quadro-poema de Bertrand e, conforme se lê em sua carta-prefácio a Arsène Houssaye, inventa "o milagre de uma prosa poética, musical, sem ritmo e sem rima, flexível e desencontrada o bastante para adaptar-se aos movimentos líricos da alma, às ondulações do devaneio, aos sobressaltos da consciência" (BAUDELAIRE 1996: 2325). Seus poemas em prosa aparecem esparsamente em revistas em 1855, 1857 e 1862, sendo reunidos em livro, postumamente, em 1869, sob o título Petits poèmes en prose Le spleen de Paris.

Baudelaire, como se sabe, não é ainda um poeta simbolista, mas suas reflexões estéticas, sua poesia em versos (Les fleurs du mal-1857) e sua recolha de poemas em prosa desbravaram os caminhos para o Simbolismo e, evidentemente, para parte considerável da poesia moderna. No que tange especificamente ao poema em prosa, este será o modelo da plêiade simbolista através de duas direções principais: a do lirismo pessoal, possível com a 任enção de uma nova linguagem (Rimbaud, Mallarmé), e a temática de inspiração urbana e contemporânea, evidente em Charles Cros ou nos Croquis parisiens (1880; 1886) de J. - K. Huysmans.

Os poemas em prosa de Arthur Rimbaud (1854 - 1891) estão coligidos em Une saison en enfer(publicado em Bruxelas, em 1873) e em Illuminations, cujos textos, escritos provavelmente entre 1873 e 1875, aparecem primeiro na revista Vogue em 1886 e, logo em seguida, numa plaquetteapresentada por Paul Verlaine. Tais poemas em prosa são exemplares da alquimia do verbo e daalucinação das palavras (RIMBAUD 1998: 161;165) exploradas pelo poeta, questões estas que se tornam claras na segunda das Cartas do vidente, endereçada a Paul Demeny em 15 de maio de 1871: “Je dis qu'il faut être voyant, se faire voyant. Le poète se fait voyant par un long, immense et raisonné dérèglement de tous les sens" (RIMBAUD 1956: 306; grifos do autor). Na mesma carta, Rimbaud afirma que o poeta moderno, "vraiment voleur de feu" (307), deve "trouver une langue" (idem) que lhe possibilite, através do processo alquímico de depuração e da liberdade ampla e irrestrita no trato com a palavra, refletir sobre a poesia e exprimir o caos de seu eu profundo, conscientemente fragmentado. Em outras 
palavras, a partir da con-fusão das percepções sensoriais, da intuição, da sugestão, da ironia e da analogia, o poeta traz à tona seu inconsciente, revelando-o em imagens fulgurantes e originais. Daí a necessidade de uma nova linguagem poética (simbólica e simbolista, analógica e dinâmica), que ofereça, simultânea e instantaneamente, em cortes rápidos, o interior e o exterior, o passado, o presente e o futuro, o natural e o artificial, o sórdido e o sublime, o eu e o outro.

Suzanne Bernard ressalta o caráter revolucionário da poesia de Rimbaud, de crucial importância na configuração do poema em prosa. Assim, entre o formalismo estrito de Bertrand e o poema em prosa solto, prosaico e irregular de Baudelaire, Rimbaud "a trouvé le point d'équilibre, et donné au poème en prose 'intense e rapide' ses lettres de noblesse poétique" (BERNARD 1959: 210).

No século XX, os surrealistas também cultuarão o poema em prosa e prezarão Rimbaud como um de seus principais precursores. Outros poetas, como Max Jacob, René Char e Francis Ponge - os dois últimos, em menor ou maior grau, herdeiros do Surrealismo -, se destacam no panorama da poesia lírica francesa em prosa, moderna e contemporânea. Max Jacob (1876 - 1944), por exemplo, abre seu livro Le cornet à dés (1916; 1923 - edição definitiva) com um prefácio sibilino e sugestivo, como a própria essência do poema em prosa: este, concebido como objeto construído, exige a efetiva participação do leitor, que deve ser transplantado. Jacob escreve ainda, em 1922, uma Art poétique que fundamenta sua obra, marcada pelo diálogo intertextual crítico, irônico e paródico com Bertrand, Baudelaire e Rimbaud, em constante atualização da tradição inventiva do poema em prosa. Francis Ponge (1899 - 1988), com Proêmes (1948), cria, através do neologismo, uma expressão eficaz - adotada depois por Octavio Paz - para qualificar sua poesia.

\section{Três}

Fora da França, no final do século XIX, é principalmente a partir da obra de Baudelaire que o poema em prosa atinge as várias literaturas ocidentais. Assim, além das traduções e paráfrases, o culto a Baudelaire levou à exploração e à experimentação de novas formas de expressão, elegendo-se o poema em prosa como veículo 
privilegiado: na América hispânica, Rubén Darío e Julián del Casal; em Portugal, João Barreira; no Brasil, Raul Pompéia, Cruz e Sousa e os simbolistas.

No Brasil, conquanto se possa rastrear as origens do poema em prosa na segunda geração do Romantismo, mais especificamente na obra menor de Vitoriano Palhares, As noites da virgem(Paris, 1868), ou na terceira parte da Lira dos vinte anos (1853), de Álvares de Azevedo (1831 - 1852) - cujo "Eutanásia" é a única experiência do poeta no gênero -, é mais acertado afirmar que o poema em prosa, entre nós, adquire melhor feição com as Canções sem metro de Raul Pompéia (1863 - 1895). Escritas a partir de 1883, quando o escritor cursava Direito em São Paulo, foram publicadas esparsamente na imprensa paulista, carioca e paranaense, e apareceram em livro apenas em 1900. As Canções sem metro, cujo título é sinônimo mesmo de Poemas em prosa, sofreram várias versões e conservam na fatura o rigor formal que sempre preocupou o escritorartista que foi Raul Pompéia, inclusive n'O Ateneu. Em suma, as Canções sem metro apresentam certa dubiedade (já trazida à tona, aliás, no texto de 1901 com que Venceslau de Queirós saúda o aparecimento do livro): pois os poemas, nitidamente aparentados, no rigor e na forma estrita, à experiência de Aloysius Bertrand e ao quadro-poema parnasiano, não deixam de ser profundamente tocados pela figura tutelar de Charles Baudelaire (veja-se, por exemplo, a seção "Vibrações", onde o poeta explora as correspondências entre cores, sons e sentimentos). Com isso, antecipam temas, motivos e preocupações que nortearão depois nossos poetas simbolistas. Além disso, coerentes com outras produções de Pompéia, as Canções sem metro apresentam, como tema recorrente, certo pessimismo à Schopenhauer.

Durante a vigência do Simbolismo, como se sabe, o poema em prosa vive seu apogeu na literatura brasileira. Mas por essa época, com exceção de Cruz e Sousa, que soube plasmar sua cosmovisão, expor seu eu profundo e definir os contornos de sua arte poética em textos memoráveis de Missal (nitidamente mais solar e brilhante, esteticista e impressionista) eEvocações (nitidamente mais noturno e soturno, metafísico e expressionista), pode-se dizer que a maioria dos poetas prendeu-se aos vezos da escola ao explorar, de forma superficial e rebuscada, os lugares-comuns decadentistas e simbolistas. Esses poetas, desconhecedores das experiências de Rimbaud, Mallarmé, Laforgue ou Lautréamont e, por outro lado, presos em excesso ao verniz nefelibata 
português, atulharam sua linguagem pretensamente nova com nebulosidades fosforescentes, imagens bíblicas e litúrgicas, acessórios florais, astrais, medievais, cabalísticos e de joalheria, numa profusão decididamente recusada pelos poetas modernistas. Tal pletora pirotécnica falsamente simbolista explica, pelo menos em parte, a crítica ferrenha ao poema em prosa no Brasil e o fato de as futuras gerações de poetas terem-no praticado com parcimônia.

Mas a parcimônia modernista - ou, melhor dizendo, sua sábia economia -, se faz com que o poema em prosa surja apenas esparsa e esporadicamente, lhe confere vasto campo de experiências, refinado humor, ferina ironia, constante diálogo intertextual com a tradição e um tom reflexivo que se coadunam à melhor poesia de nosso Modernismo. Veja-se, pontualmente, Bandeira, Drummond e Mário Quintana.

Na cena contemporânea, o poema em prosa exprime muito bem os anseios pósmodernos dos poetas norte-americanos, que pelo menos desde a década de 60 a ele têmse dedicado com afinco (Russell Edson, Michael Benedikt, Charles Simic), escrevendo suas obras e publicando antologias onde se preocupam em definir - e em legitimar essa que se tornou, segundo Robert Alexander, “in Donald Hall's words, 'a dominant American literary form'” (1996: 5). De sua parte, a crítica Margueritte S. Murphy considera o poema em prosa um gênero subversivo (desde as origens), pós-moderno e dialógico por excelência. A estudiosa observa que a tradição do poema em prosa angloamericano é errática e idiossincrática, pois não teve, como na França, o fermento dos poetas românticos e simbolistas para se desenvolver. Pode-se dizer que o caminho trilhado pelo poema em prosa nas literaturas de língua portuguesa também foi irregular e particular, mas a discussão contemporânea, pelo menos no Brasil, não o considera como veículo estrito da pós-modernidade lírica. Ao contrário: o recém-publicado ensaio "Poesia e pós-modernidade", de Ricardo Araújo (em $O$ pós-Modernismo, 2005), considera como estritamente pós-modernas as experimentações radicais da poesia visual, da vídeo-poesia ou da infopoesia. Herdeiras incontestes do Concretismo, tais formas levam ao paroxismo o arsenal estético conquistado por aquele: o apreço pelo estrato visual, a estrutura verbivocovisual, o aporte e o suporte tecnológicos, a intersemiose, o rigor, a "sobreposição do analógico ao irônico" (ARAÚJO 2005: 298). 
A meu ver, o ensaísta tem certa razão, mesmo porque o poema em prosa no Brasil nunca foi tão revolucionário quanto o foi na França (exceto, talvez, no que tange à obra de Cruz e Sousa), cabendo a nosso Modernismo e à poesia concretista, por consenso, o papel de revoluções estéticas permanentes. Contudo, vários e contraditórios são os caminhos da poesia contemporânea no Brasil, e ao lado dos herdeiros do Concretismo há os que recuperam os cacos da tradição clássica e medieval, atualizando formas, temas e motivos; e há os que fazem do poema em prosa (ao lado do poema em versos, ou mesmo da narrativa) um meio específico de construir poesia. Cito, pontualmente, as experiências de Rubens Rodrigues Torres Filho, Cláudio Willer, Zulmira Ribeiro Tavares. Com isso, o poema em prosa no Brasil adquiriu foros privilegiados de reflexão sobre a própria poesia, o poeta, o mundo, a vida e o eu, instâncias sempre sujeitas à liqüidificação contemporânea.

\section{OBRAS CITADAS}

ALEXANDER, R. et al, eds. 1996. The party train: a collection of North American prose poetry. Minneapolis: New Rivers.

ARAÚJO, R. 2005. Poesia e pós-modernidade. In: GUINSBURG, J., \& BARBOSA, Ana Mae, org. O pós-modernismo. Stylus 12. São Paulo: Perspectiva. 295-314.

BAUDELAIRE, C. 1996. Pequenos poemas em prosa. Tradução de Dorothé de Bruchard. Florianópolis: UFSC.

BERNARD, S. 1959. Le poème en prose de Baudelaire jusqu'à nos jours. Paris: Nizet.

CRUZ E SOUSA, J. da. 1995. Obra completa. Rio de Janeiro: Nova Aguilar.

FRIEDRICH, H. 1991. Estrutura da lírica moderna. São Paulo: Duas Cidades.

MURPHY, M. S. 1992. A tradition of subversion: the prose poem in English from Wilde to Ashbery. Massachusetts: U of Massachusetts P.

PAZ, O. 1974. Los hijos del limo: del romanticismo a la vanguardia. Barcelona: Seix Barral. 2001. A outra voz. São Paulo: Siciliano, 2001. 1996. Signos em rotação. Debates 48. São Paulo: Perspectiva.

POMPÉIA, R. 1982. Canções sem metro. Vol. 4. Rio de Janeiro: Civilização Brasileira/OLAC. 
POUND, E. 1989. ABC da literatura. São Paulo: Cultrix.

RIMBAUD, A. 1956. Oeuvres. Paris: Mercure de France. 1 998. Prosa poética. Rio de Janeiro: Topbooks. 